\title{
Clinical and aetiological study of adenoviral conjunctivitis, with special reference to adenovirus types 4 and 19 infections
}

\author{
KOKI AOKI,' MICHIO KATO, ${ }^{1}$ HIDEO OHTSUKA, ${ }^{1}$ KEIZO ISHII, ${ }^{2}$ \\ NAOKI NAKAZONO, ${ }^{2}$ AND HARUMI SAWADA ${ }^{2}$ \\ From the 'Eye Hospital, Sapporo City, and the ${ }^{2}$ Department of Public Health, \\ Hokkaido University School of Medicine, Sapporo, Japan
}

SUMmARY The clinical and aetiological findings are presented on 343 patients with clinical adenoviral conjunctivitis treated between July 1979 and July 1980 at 3 eye clinics in Sapporo. The age of the patients ranged from 12 days to 79 years, and the monthly incidence of the disease from 9 to 83 , with clustering in the summer season. The aetiological diagnosis was established in $196(57 \%)$ of 343 patients: adenovirus 3 in 24 cases; adenovirus 4 in 33 cases, including one case serologically diagnosed; adenovirus 8 in 124 cases; and adenovirus 19 in 15 cases. The different serotypes caused different clinical pictures. Adenovirus 19 conjunctivitis was more severe, with keratitis and preauricular lymphadenopathy more frequent than that of adenovirus 3 conjunctivitis. Adenovirus 4 conjunctivitis was generally similar to adenovirus 3 conjunctivitis. The clinical difference between the 2 groups adenoviruses 3 and 4 , and adenoviruses 8 and 9 , was statistically significant. Although in Japan adenovirus 8 was the most prevalent, adenoviruses 4 and 19 should be considered as causative agents of adenoviral conjunctivitis.

Adenoviral conjunctivitis is now known to be caused by many adenovirus serotypes. We have therefore studied the relationship between the various pathogenic viruses and their clinical consequences. This project was started in 1974, and the results have been reported up to $1978 .{ }^{1}$ During the course of further study we found several pathogenic viruses, including adenovirus 4 and 19. No enterovirus (EV) 70 was detected, though this had been found in a previous investigation. The present paper describes the results of an aetiological and clinical study of viral conjunctivitis from July 1979 to 1980 in Sapporo, Japan, with emphasis on the infections caused by adenoviruses 4 and 19.

\section{Material and methods}

SUBJECTS

The subjects were patients who were clinically suspected of having viral conjunctivitis, associated with epidemic keratoconjunctivitis (EKC), acute

Correspondence to Dr K. Aoki, Aoki Eye Hospital, 6 Hondori, Shiroishi-ku, Sapporo 003, Japan. haemorrhagic conjunctivitis (AHC), or pharyngeal conjunctival fever (PCF) when they were first examined at the 3 clinics (K.A., M.K., and H.O.) in Sapporo. The patients were examined throughout the year, including times of high clinical incidence. 343 were observed during the period of 13 months from July 1979 , with ages ranging from 12 days to 79 years. The dates of onset were classified by month (Table 1 ). Persons without complete clinical follow-up were excluded from the detailed analysis.

\section{AETIOLOGY}

Virus isolation. Conjunctival swabs were collected at the first visit and were suspended in a sterile tube containing transport medium and frozen for storage until tested. HeLa cells were used for viral isolation throughout the study, and HEK cells were also used in the latter half of the study. Both HeLa and HEK cells were used for viral isolation in all the specimens obtained in 1980. The appearance of cytopathic effects (CPE) was always slower in HeLa cells than in HEK cells, but no difference was noted in isolation rates in types other than adenovirus 8 . The isolation 
Table 1 Number of patients with adenoviral conjunctivitus due to specific type of virus and month of onset

\begin{tabular}{|c|c|c|c|c|c|c|c|}
\hline Month & $\begin{array}{l}\text { Number of } \\
\text { patients }\end{array}$ & Ad 3 & Ad 4 & Ad 8 & Ad 19 & $\begin{array}{l}\text { AdV } \\
\text { infection* }\end{array}$ & $\begin{array}{l}\text { Diagnosis } \\
\text { unknown }\end{array}$ \\
\hline July 1979 & 9 & & 1 & 4 & & & $4^{\dagger}$ \\
\hline Aug. & 50 & 11 & 11 & 12 & 1 & 1 & $14 \ddagger$ \\
\hline Sep. & 25 & 4 & 4 & 8 & & 2 & 7 \\
\hline Oct. & 23 & 1 & $1^{*}$ & 8 & & 3 & .10 \\
\hline Nov. & 14 & & 4 & 7 & & 1 & 2 \\
\hline Dec. & 10 & & 3 & 3 & 1 & & 3 \\
\hline Jan. 1980 & 19 & & 1 & 4 & 5 & & 9 \\
\hline Feb. & 9 & & 1 & 1 & 1 & 2 & 4 \\
\hline Mar. & 9 & & & 4 & & 1 & 4 \\
\hline Apr. & 9 & 3 & & 1 & 1 & & 4 \\
\hline May & 27 & 1 & 2 & 11 & 1 & & 12 \\
\hline June & 56 & 2 & 2 & 17 & & 7 & 28 \\
\hline July & 83 & 2 & 3 & 44 & 5 & 8 & 21 \\
\hline Total & 343 & 24 & 33 & 124 & 15 & 25 & 122 \\
\hline
\end{tabular}

${ }^{*}$ Diagnosed by $\mathrm{Cf}$ and/or neutralization tests.

tIncluded one case with EV 70 serologically diagnosed.

$\ddagger$ Included one case with CA 9 isolated.

of adenovirus 8 in HeLa cells decreased approximately $40 \%$ in rate in comparison with that in HEK cells.

The cell culture tubes in which conjunctival swabs were inoculated were cultivated by rotation at $33^{\circ} \mathrm{C}$, and CPE was looked for daily. The inocula were cultured for at least 2 passages before the results of isolation were considered negative, no CPE being observed. The CPE agents were identified by neutralisation tests by microtitre techniques and antisera to various types of human adenovirus.

Serological tests. Serum was taken at the first visit and convalescent serum at intervals of 10 days or more, when possible. The paired sera were collected in 185 cases $(54 \%)$. The measurement of adenoviral antibody in paired sera was simultaneously carried out by means of the complement fixation test (CF), with $\mathrm{CF}$ antigen prepared with adenovirus 3 . In addition the neutralising antibody to adenovirus 4 was also measured in some paired sera with a 4-fold increase in the titre of CF antibody in convalescent serum being considered significant.

\section{Results}

\section{TYPES OF ADENOVIRUS IDENTIFIED}

Virus isolation was attempted in a total of 343 cases of viral conjunctivitis during the study period, and 195 strains $(57 \%)$ of adenovirus were isolated from the conjunctival swabs. In addition one case with adenovirus 4 was detected by a 4 -fold increase in neutralisation test (NT) antibody titre and 2 cases with enteroviruses, EV 70 and Coxsackie virus A9, were found by virus isolation or serological testing. In addition 25 cases with adenovirus infection were diagnosed by the $\mathrm{CF}$ tests. In all, infections with different types of adenovirus were detected in 196 cases (57\%): adenovirus 3 in 24 cases, adenovirus 4 in 33 cases, adenovirus 8 in 124 cases, and adenovirus 19 in 15 cases. The results are shown in terms of month of onset in Table 1.

\section{MONTHLY INCIDENCE}

The incidence of adenovirus conjunctivitis ranged from 9 to 83 cases with a clustering in the summer season. Although adenovirus 8 was isolated in every month, types other than adenovirus 8 were isolated only in certain months during the study period. Adenoviruses 3 and 4 tended to prevail in 1979, and adenovirus 19 in 1980, but in a particular month or in a particular clinic no one type was solely isolated. Adenovirus 4 was first isolated in our current study, whereas one strain, adenovirus 19 , had previously been detected in $1978 .^{1}$

\section{AGE DISTRIBUTION BY VIRAL TYPES}

The age distribution and the types of isolates from the patients is shown in Table 2, with the 20-39 age group being the most common. The rate of viral isolation by age group varied from $41 \%$ to $68 \%$, with the $0-9$ age group being the lowest. Adenovirus 19 was not found

Table 2 Age distribution of patients with adenoviral conjunctivitis by serotypes

\begin{tabular}{lcccccc}
\hline \multirow{2}{*}{$\begin{array}{l}\text { Age } \\
\text { group }\end{array}$} & $\begin{array}{l}\text { Number } \\
\text { tested }\end{array}$ & \multicolumn{2}{l}{ Virus type isolated } & \multirow{2}{*}{ Total (\%) } \\
\cline { 3 - 6 } & & Ad 3 & Ad 4 & Ad 8 & Ad 19 & \\
\hline $0-9$ & 39 & 4 & 1 & 9 & 2 & $16(41 \%)$ \\
$10-19$ & 37 & 3 & 6 & 11 & 2 & $22(59 \%)$ \\
$20-39$ & 155 & 12 & 22 & 52 & 11 & $97(63 \%)$ \\
$40-59$ & 64 & 3 & 1 & 27 & & $31(48 \%)$ \\
$61-$ & 48 & 2 & 3 & 25 & & $30(68 \%)$ \\
\hline
\end{tabular}


Table 3 Isolation rate of adenoviruses per day after onset of symptoms

\begin{tabular}{lrrrrrrr}
\hline $\begin{array}{l}\text { Day after } \\
\text { onset }\end{array}$ & $\begin{array}{l}\text { Number } \\
\text { tested }\end{array}$ & \multicolumn{3}{c}{ Virus types isolated } & \multicolumn{2}{c}{ Total (\%) } \\
\cline { 3 - 6 } & & Ad 3 & Ad 4 & Ad 8 & Ad 19 \\
\hline $1-4$ & 229 & 16 & 22 & 85 & 10 & $133(58 \%)$ \\
$5-7$ & 66 & 3 & 8 & 21 & 2 & $34(52 \%)$ \\
$8-14$ & 44 & 2 & 2 & 18 & 3 & $25(57 \%)$ \\
$15-$ & 10 & 3 & & & & $3(30 \%)$ \\
Total & & 24 & 32 & 124 & 15 & \\
\hline
\end{tabular}

in patients over 40 years of age, although all other types of adenovirus were more widely dispersed throughout the age groups, with adenoviruses 3 and 4 tending to be found in the patients under 40 and adenovirus 8 in the older patients.

\section{FREQUENCY OF VIRUS ISOLATION IN THE}

CLINICAL STAGE

One hundred and ninety-five strains $(56 \%)$ of adenovirus were isolated from 349 specimens of conjunctival swabs. The isolation rates in terms of days after onset of symptoms are shown in Table 3. The specimens were generally first collected at an early stage of infection, but the isolation rates were $52 \%-58 \%$ up to the second week after onset of symptoms. There was no particular virus type which showed a marked decline in the isolation rate over this 2-week period. All 3 strains isolated from 10 specimens obtained on the 15th day or later after onset were adenovirus 3 . It was noteworthy that adenovirus was excreted from the conjunctiva for a longer period than EV 70, which was not detected after the fifth day after onset in our previous study. ${ }^{1}$

\section{CLINICAL SIGNS AND SYMPTOMS}

Conjunctivitis. The association between severity of conjunctivitis and viral types is presented in Table 4. The incidence of mild conjunctivitis was highest in adenovirus 3 infection (45\% or 9 out of 20 ), followed by adenovirus $4(29 \%)$, while the highest rate of severe conjunctivitis was observed in adenovirus 8 infection ( $42 \%$ or 49 out of 117 ), followed by $40 \%$ of

Table 4 Severity of conjunctivitis according to the types of adenovirus infections

\begin{tabular}{lrrrr}
\hline $\begin{array}{l}\text { Severity of } \\
\text { conjunctivitis }\end{array}$ & Ad $3^{*}$ & Ad 4 & Ad $8^{*}$ & Ad 19* \\
\hline Number examined $t$ & 20 & 28 & 117 & 15 \\
+ & 9 & 8 & 18 & 0 \\
++ & 9 & 12 & 50 & 9 \\
+++ & 2 & 8 & 49 & 6 \\
\hline
\end{tabular}

${ }^{*} \mathrm{p}<0.01$.

†Excludes persons without complete clinical follow-up.
Table 5 Frequency of keratitis and preauricular lymphadonopathy according to the types of adenovirus infections

\begin{tabular}{llcccc}
\hline Signs & & Ad 3 & Ad 4 & Ad 8 & Ad 19 \\
\hline Keratitis & $\begin{array}{l}\text { Number } \\
\text { examined } \ddagger\end{array}$ & 11 & 11 & 99 & 10 \\
& $\begin{array}{l}\text { No } \\
\text { Yes }\end{array}$ & $10^{\dagger}$ & $8^{*}$ & $39^{* \dagger}$ & $3^{* \dagger}$ \\
& $(\%)$ & $(9 \cdot 1)$ & $(27 \cdot 3)$ & $(60 \cdot 6)$ & $(70 \cdot 0)$ \\
\hline Preauricular & Number & 20 & 32 & 114 & 14 \\
lymphadenopathy & examined $\ddagger$ & & & & \\
& No & 16 & 21 & 64 & 5 \\
& Yes & 4 & 11 & 50 & 9 \\
& $(\%)$ & $(20 \cdot 0)$ & $(34 \cdot 3)$ & $(43 \cdot 9)$ & $(64 \cdot 3)$ \\
\hline & & & & &
\end{tabular}

${ }^{*} p<0.05$

$+\mathrm{p}<0.05$.

$\ddagger$ Excludes persons without complete clinical follow-up.

adenovirus 19 cases. In comparison, the conjunctivitis of adenovirus 3 was significantly milder than that of both adenoviruses 8 and $19(\mathrm{p}<0.01)$. When the infections with adenoviruses 3 and 4 were compared in terms of severity of conjunctivitis with those of adenoviruses 8 and 19, there was a significant difference $(p<0.02)$ between the 2 groups.

Keratitis. The keratitis associated with conjunctivitis is shown in Table 5. Keratitis caused by adenoviruses 3 or 4 was significantly less frequent $(9 \%$ or $27 \%$ ) than that caused by adenoviruses 8 or 19 . When the incidence of keratitis was calculated by dividing the patients into 2 groups, adenoviruses 3 and 4 on the one hand and adenoviruses 8 and 19 on the other, a significant difference $(p<0.001)$ was found between the 2 , a trend similar to that observed in the severity of conjunctivitis.

Preauricular lymphadenopathy. The frequency of preauricular lymphadenopathy is shown in Table 5, being only $20-34 \%$ in adenoviruses 3 and 4 infections, but significantly higher at $44-64 \%$ in adenoviruses 8 and 19 infections.

Subconjunctival haemorrhage. The lowest incidence was $5 \%$ (one patient) in those with adenovirus 3 infection, but it was more frequent (13-21\%) in the other viral types.

Extraocular symptoms and signs. Extraocular symptoms were found most frequently in those with adenovirus 4 infections $(36 \%)$ and less frequently $(7-17 \%)$ in those with other types of infection. Fever in adenovirus 4 infection was noted in 9 out of 20 patients, which was significantly higher than the incidence found in adenoviruses 3 or 8 ( 2 and 5). Each serotype of adenovirus caused a few cases of upper respiratory illness, such as pharyngitis or the common cold, and there were also a few cases of diaarrhoeasurprisingly few in adenovirus 3 conjunctivitis. 
Subjective symptoms. Symptoms were found in patients regardless of the type of adenovirus causing their symptoms. Congestion and eye discharge were observed in most cases, with lacrimation in some, while lid swelling was most frequently complained of in adenoviruses 8 and 4 infections. Foreign body sensation was complained of in cases of adenovirus 8 and a few with adenoviruses 4 or 19 , and eye pain and blurring of vision were found in one case with adenovirus 8 infection.

\section{Discussion}

A collaborative study of viral conjunctivitis has been continued in Sapporo, northern Japan, since 1974. This is the second report in which the subject of the study was extended to adenoviruses as well as entero viruses such as EV 70 , since outbreaks of conjunctivitis due to adenovirus 19 have been reported in Europe and America. ${ }^{2-5}$ In this study from 1979 to July 1980 viral isolates were obtained from 195 out of 343 patients with clinically diagnosed adenovirus infection, comprising 24 cases of adenovirus 3, 32 with adenovirus 4,124 with adenovirus 8 , and 15 with adenovirus 19 . We have previously reported a single case with adenovirus $19^{1}$ but never a case of adenovirus-4-induced conjunctivitis. The study has shown that the severity of conjunctivitis and the incidence of keratitis and lymphadenopathy is less in those infections caused by adenoviruses 3 or 4 than in those cases caused by adenoviruses 8 or 19 . In general the incidence of subconjunctival haemorrhage was less in all types of adenovirus infection of this study than in the previous one of EV 70. In addition no subconjunctival ecchymoses were found in these cases of adenovirus conjunctivitis, though it is commoner in EV 70 conjunctivitis. The low incidence of extraocular signs with adenovirus 3 conjunctivitis may be based on the fact that patients with typical pharyngeal conjunctival fever attended a paediatric clinic.

Conjunctivitis or keratoconjunctivitis due to adenovirus 19 has been detected in several European countries $^{25}$ and in parts of America ${ }^{34}$ during the first half of the 1970s. Then ocular infections with adenovirus 19 were continually reported from Europe $^{\sigma-9}$ and the United States ${ }^{10-12}$ and more recently from Australia..$^{13}$ In more recent years this virus type has been widespread about the world. Wadell and de Jong ${ }^{14}$ have reported that the isolates of adenovirus 19 in Europe in 1973 were heterogeneous for the prototype strain of adenovirus 19 when studied by means of restriction enzyme analysis. It has also been reported that some strains of current isolates from ocular infections were not adenovirus 19 itself but intermediate types between 19 and 10 , when serological tests were used. ${ }^{89}$ Although the reasons for the worldwide spread of adenovirus 19 in recent years are unknown, it may be caused by molecular or serological differences of the current strain from the classical prototype strains.

It is generally recognised that adenovirus 19 infection is associated with epidemic keratoconjunctivitis (EKC) ${ }^{4}$ and occasionally with acute haemorrhagic conjunctivitis (AHC) ${ }^{3}$ In this study the clinical manifestations of adenovirus 19 infection were similar to those of adenovirus 8 infection. A clinical AHC-like illness from adenovirus 19 has been reported by us ${ }^{1}$ and by Higuchi $e$ t al. ${ }^{15}$ though there has been no PCF-like illness with adenovirus 19 in Japan. A variety of clinical symptoms of adenovirus 19 infection were found in a hospital outbreak,,$^{16}$ and this infection has been notable for its spread among younger age groups, usually between 11 and 40 years of age, which is in agreement with the findings of Vastine et al. ${ }^{12}$

For a long time adenovirus 4 has been a welldocumented cause of acute respiratory illness with fever, though it has been reported in Taiwan ${ }^{17}$ that this virus may cause only conjunctivitis. In Melbourne from 1969 to 1971 the virus was detected more frequently in patients with upper respiratory tract illnesses than in those with simply conjunctivitis or PCF. ${ }^{18}$ Recently, however, reports on adenovirus 4 ocular disease have increased in both Europe and America, namely, AHC in Rome,$^{19}$ conjunctivitis in Bristol $^{20}$ and in Chicago, ${ }^{21}$ and PCF from a swimming-pool source in the United States. ${ }^{22}$ In this study adenovirus 4 was detected in 33 cases in most months of the study period. The nation-wide dissemination of adenovirus 4 was suggested because of outbreaks of acute respiratory disease or pharyngeal conjunctival fever due to adenovirus infection in children, occurring in various parts of Japan in 1979 and 1980 . In this study adenovirus-4-induced conjunctivitis was found throughout all age groups, and the wide age distribution reflects the finding that the NT antibody to adenovirus 4 was in only $23 \%$ of adult sera by serosurvey conducted just before the outbreaks (Wanabe M, Yamada F, unpublished). In this we found the clinical manifestations of adenovirus 4 infection to be similar to those of adenovirus 3 infection, though patients with adenovirus 4 were more frequently febrile than those with adenovirus 3 .

Since both adenoviruses 4 and 19 were detected from conjunctival swabs, and as they have also been found as causative agents in Europe and the United States, we suggest that the aetiological pattern of viral conjunctivitis in Japan is similar to that of Europe and the United States, except that EV 70 has only quite recently been introduced for the first time into the United States. ${ }^{23}$ 


\section{References}

1 Aoki K, Kato M, Ohtsuka H, et al. Clinical and etiological study of viral conjunctivitis 1974-1978, Sapporo, Japan. Jpn J Ophthalmol 1980; 24: 149-59.

2 Desmyter J, de Jong J, Slaterns KW, Verlaecki H. Keratoconjunctivitis caused by adenovirus type 19. Br Med J 1974; iv: 406.

3 Taylor JW, Chandler JW, Cooney MK. Acute hemorrhagic conjunctivitis associated with adenovirus type 19. N Engl J Med 1975; 292: 978-9.

4 Dawson CR, O'Day D, Vastine D. Adenovirus 19, a cause of epidemic keratoconjunctivitis, not acute hemorrhagic conjunctivitis. N Engl J Med 1975; 293: 45-6.

5 Darougar S, Quinlan MP, Gibson JA, Jones BR, McSwiggan DA. Epidemic keratoconjunctivitis and chronic papillary conjunctivitis in London due to adenovirus type 19. Br J Ophthalmol 1977; 61: 76-85.

6 Wigand R, Bruch P, Trauzettel S, Sundmacher R. Virological diagnosis of epidemic keratoconjunctivitis. Zentralbl Bakteriol (Orig A) 1979; 245: 395-408.

7 Colin J, Gribson AL, Renard G, Chastel C, Chomel JJ, Aymard M. Ocular infection caused by adenovirus 19. J Fr Ophtalmol $1980 ; 3$ : 357-8.

8 Tullo AB, Higgins PG. An outbreak of adenovirus keratoconjunctivitis in Bristol. Br J Ophthalmol 1979; 63: 621-6.

9 Schaap GJ, de Jong JC, van Bijsterveld OP, Beekhuis WH. A new intermediated adenovirus type causing conjunctivitis. Arch Ophthalmol 1979; 97: 2336-8.

10 O'Day DM, Guyer B, Hierholzer JC, Rosing KJ, Schaffner W. Clinical and laboratory evaluation of epidemic keratoconjunctivitis due to adenovirus types 8 and 19. Am J Ophthalmol 1976; 81: 207-15.

11 Taylor JW, Chandler JW, Cooney MK. Conjunctivitis due to adenovirus type 19. J Clin Microbiol 1978; 8: 209-13.
12 Vastine DW, West CE, Yamashiroya $\mathrm{H}$, et al. Simultaneous nosocomial and community outbreak of epidemic keratoconjunctivitis with types 8 and 19 adenovirus. Trans Am Acad Ophthalmol Otolaryngol 1976; 81: 826-40.

13 Irving L, Kennett M, Lewis F, Birch C, Donaldson A. Adenovirus eye infections in an Australian city, 1972-9. J Hyg (Camb) 1981; 86: 95-103.

14 Wadell G, de Jong JC. Restriction endonucleases in identification of a genome type of adenovirus 19 associated with keratoconjunctivitis. Infect Immun 1980; 27: 292-6.

15 Higuchi M, Ohno S, Nakazono N, Ishida M, Ishii K. An etiological study on acute conjunctivitis. Folia Ophthalmol Jpn 1981; 32: 2152-7.

16 Harrison MR, Howe P, Munich L, Ray CG. A cluster of adenovirus 19 infection with multiple clinical manifestations. $J$ Pediatr 1979; 94: 917-9.

17 Grayston JH, Yang Y-F, Johnson PB, Ko L-S. Epidemic keratoconjunctivitis on Taiwan: etiological and clinical studies. Am J Trop Med Hyg 1964; 13: 492-8.

18 Ellis AW, McKinnon GT, Lewis FA, Gust ID. Adenovirus type 4 in Melbourne, 1967-71. Med J Aust 1974; i: 209-11.

19 Muzzi A, Rocchi G, Lumbroso B, Josato G, Barbieri F. Acute haemorrhagic conjunctivitis during an epidemic outbreak of adenovirus type 4 infection. Lancet 1975; ii: 822-3.

20 Tullo AB, Higgins PG. An outbreak of adenovirus type 4 conjunctivitis. Br J Ophthalmol 1980; 64: 489-93.

21 Levandowski RA, Rubenis M. Nosocomial conjunctivitis caused by adenovirus type 4 . $J$ Infect $D$ is $1981 ; 143: 28-31$.

22 D'Angelo LJ, Hierholzer JC, Keenlyside RA, Anderson LJ, Martone WJ. Pharyngoconjunctival fever caused by adenovirus type 4: report of a swimming pool related outbreak with recovering of virus from pool water. J Infect Dis 1979; 140: 42-7.

$23 \mathrm{CDC}$ Isolation of enterovirus $\mathbf{7 0}$ from acute hemorrhagic conjunctivitis-Key West, Florida. Morbidity and Mortality Weekly Report 1981; 30: 497. 